\title{
CORRECTION
}

\section{Correction: Lung mechanics and respiratory morbidities in school-age children born moderate-to-late preterm}

Fabianne M. N. A. Dantas, Paulo A. F. Magalhães, Emilly C. N. Hora, Lívia B. Andrade, José Ângelo Rizzo, Décio M. Peixoto and Emanuel S. C. Sarinho

Pediatric Research (2022) 91:1300; https://doi.org/10.1038/s41390-021-01599-z

Correction to: Pediatric Research https://doi.org/10.1038/s41390021-01538-y, published online 8 May 2021

Due to a processing error, the affiliations were incorrect and one affiliation was missing.

The correct information is given below. The original article has been corrected.

Fabianne M. N. A. Dantas ${ }^{1,2}$, Paulo A. F. Magalhães ${ }^{1,2,3}$, Emilly C. N. Hora ${ }^{4}$, Lívia B. Andrade ${ }^{5}$, José Ângelo Rizzo ${ }^{6}$, Décio M. Peixoto ${ }^{6}$ and Emanuel S. C. Sarinho ${ }^{6}$
${ }^{1}$ Research Group of Neonatal and Pediatric Physical Therapy, Baby GrUPE, Petrolina, Pernambuco, Brazil; ${ }^{2}$ Department of Physical Therapy, Universidade de Pernambuco, Petrolina, Pernambuco, Brazil; ${ }^{3}$ Graduate Program in Rehabilitation and Functional Performance, Universidade de Pernambuco, Petrolina, Pernambuco, Brazil; ${ }^{4}$ Universidade Federal de Sergipe, Aracaju, Sergipe, Brazil, ${ }^{5}$ Professor Fernando Figueira Integral Medicine Institute, Recife, Pernambuco, Brazil and ${ }^{6}$ Universidade Federal de Pernambuco, Recife, Pernambuco, Brazil 